\title{
Content Analyses of Scientific Articles from Issues Published in Sport Mont Journal in 2012
}

\author{
Jovan Radulovic \\ University of Montenegro, Faculty for Sport and Physical Education, Niksic, Montenegro
}

\begin{abstract}
A B S T R A C T
Sport Mont Journal is an electronic and printed scientific journal aimed at facilitating access to scientific knowledge for the purpose of raising global awareness of sports. So far, more than 1000 scientific papers from around the world have been published. Sport Mont Journal is indexed in over 23 international databases. Scopus is one of the most prestigious bases, making clear the quality of this magazine. Sport Mont covers all aspects of sports science and medicine, all clinical aspects of exercise, health and sport, physiology and biophysical search of sports performances, biomechanics, sports nutrition, rehabilitation, physical therapy, sports psychology, sports pedagogy, sports history, sports philosophy, sociology of sports, sports management and all aspects of scientific support to sports trainers from the natural, social and humanistic side. The aim of the paper was to classify titles in their fields of science. The sample of this research consisted of 94 titles, Sport Mont Journal published in 2012. The method of content analysis concluded that the most read works from the anthropology of sports - 45, then research in sport and sociopsychology - 14, then sports methodology, education and sports, management and marketing in sport - 18, the field of biomechanics includes - 4, physiology of sport - 2, methodology - 3, and, ultimately, sports medicine - 7. It should be noted that the authors of these works were from the whole region, and even wider.
\end{abstract}

Key words: Sport science, Sport Mont Journal

\section{Uvod}

Sport Mont Journal je elektronski i štampani naučni časopis čiji je cilj da omogući lakši pristup naučnim saznanjima u svrhu podizanja globalne sportske svijesti. Od 2003. godine, otkako je osnovan, objavljeno je više od 1000 naučnih radova, a sam časopis obezbjeđuje otvoren on-line pristup, brzo vrijeme objavljivanja, recenzije stručnjaka, vježbe istraživača. Sport Mont Journal je indeksiran u preko 23 međunarodne baze podataka, od kojih je Scopus najprestižnija baza. Dinamika ovog časopisa je objavljivanje tri puta godišnje, u februaru, junu i oktobru, svake godine. Ovaj časopis objavljuje originalne naučne radove, pregledne radove, uvodnike, kratke izvještaje, kao i poziv i nagrade radova u oblasti sportskih nauka i medicine, i funkcioniše kao otvoreni forum za diskusiju o značajnim aktuelnim pitanjima. Sport Mont Journal pokriva sve aspekte sportske nauke i medicine, sve aspekte vježbanja, zdravlja i sporta, fiziologiju i biofizičku pretragu sportskih performansi, biomehaniku, sportsku ishranu, rehabilitaciju, fizikalnu terapiju, sportsku psihologiju, sportsku pedagogiju, sportsku istoriju, sportsku filozofiju, sociologiju sporta, sportski menadžment i sve aspekte naučne podrške sportskim trenerima sa prirodne, društvene i humanističke strane. Sport Mont Journal je zvanični časopis Crnogorske sportske akademije i objavljuje se u saradnji sa Fakultetom za sport i fizičko vaspitanje iz Nikšića. Časopis je indeksiran u bazama EBSCO Publishing Inc, Index Copernicus, ERIH PLUS, Universal Impact Factor, Open Academic Journals Index, InoBase Index, SafetzLit, Electronic Journals Librarz, UB Leipzig, Merchurst University Libraries, EZB (Elekronische Zeitschriftenbibliothek), WZB Berlin Social Science Center, Genamics JournalSeek, UTS: Librarz, Global Impact Factor, Google Scholar, Scintiic Indexing Services, ROAD, CiteFac- ctor and Journal Impacct Faktor, što govori u prilog činjenici da je ovaj časopis jedan od najkonkurentnijih časopisa. Sport Mont Journal vezan je za naučnu konferenciju koju Univerzitet Crne Gore i Crnogorska sportska akademija odnedavno organizuju u Budvi, dok je proteklih godina organizovana u Podgorici, gdje svoja istraživanja i predavanja izlažu međunarodno priznati profesori i naučnici.

Glavni cilj ovog rada je razvrstati članke iz časopisa Sport Mont Journal, objavljenih 2012. godine, po naučnim oblastima, odnosno disciplinama kojim pripadaju.

\section{Metoda rada}

U ovom radu uzorak sačinjavaju članci, odnosno naslovi objavljeni 2012. godine u Sport Mont Journal, koji će biti razvrstani metodom analize sadržaja.

Analiza sadržaja je prepoznata metoda za objektivnu sistemsku i kvantitativnu analizu očiglednog sadržaja saopštenja (štampe, knjiga, filmova, kao i elektronskih sadržaja). U 2012. godini objavljena su ukupno 94 naučna rada sabrana u oblastima fiziologije sporta, sportske medicine, biomehanike, antropologije, istraživanja u sportu i sociopsihologije, metodologije, radovi iz oblasti sportske metodike, obrazovanje i sport, menadžment i marketing u sportu.

Tamo gdje god postoji više činilaca, koji nose jedan zajednički smisao, kao što je u ovom slučaju sport kao zajedničko obilježje, a sportske discipline kao mnoštvo činilaca, neophodno je izvršiti sistematizaciju svih činilaca i razvrstati ih po najtipičnijem obilježju. (Bjelica, \& Fratrić, 2011). 


\section{Rezultati}

Analizom, odnosno razvrstavanjem radova iz časopisa
Sport Mont, po naučnim oblastima, objavljenih 2012. godine, rezultati će biti prikazani u slijedećoj tabeli:

Tabela 1. Podjela radova prema oblastima

\begin{tabular}{cc}
\hline Oblasti & Broj radova \\
\hline Antropologija sporta & 45 \\
Istraživanja u sportu i sociopsihologiji & 15 \\
Sportska metodika, obrazovanje i sport, menadžment i & 18 \\
marketing u sportu & \\
Biomehanika & 4 \\
Fiziologija sporta & 2 \\
Metodologija & 3 \\
Sportska medicina & 7 \\
\hline
\end{tabular}

Pomenutom analizom svih radova i nakon tabelarnog prikaza, zaključuje se da je najviše radova bilo je iz antropologije sporta, koja proučava veze između određenih disciplina, karakteristika sporta, a prije svega, antropologija je nauka o čovjeku. Ova naučna oblast u Sport Mont časopisu je bila zastupljena kroz slijedeće radove: "Razlika u manifestaciji eksplozivne snage nogu u odnosu na status uzdužnog svoda stopala mladih atletičara" (Mihajlović, Petrović, \& Šolaja, 2012), "Relacije tjelesne kompozicije i motoričkih sposobnosti kod djece uzrasta do 7 godina" (Halasi, \& Lepeš, 2012), "Uticaj izbornih programa odbojke i košarke na transformaciju biomotoričkih sposobnosti učenika" (Kljajević, 2012), "Kvantitativne razlike u savladavanju motoričkih testova kod studentima iz Makedonije i Republike Srbije" (Georgiev, Kostovski, \& Mitrevski, 2012), "Relacije između antropometrijskih, motoričkih i ritmičkih varijabli kod studentata uzrasta 19-20 godina" (Damjanovska, 2012), "Razlike u statičkoj snazi rekreativnih i vrhunskih sprintera" (Čoh, Žvan, \& Burnik, 2012), "Razlike između rukometaša kadeta i mlađih kadeta u pokazateljima specifičnih motoričkih sposobnosti" (Milanović, \& Nikolić, 2012), "Uticaj nastavnih sadržaja ritmičke gimnastike na razvoj nekih motoričkih sposobnosti učenica petog razreda osnovne škole" (Vujović, 2012). "Validnost situacijsko-motoričkih testova kod fudbalera kadeta u dobi od 15 godina (U15)" (Gardašević, \& Bjelica, 2012), "Osnovne motoričke sposobnosti i situacijona motorička efikasnost kod mladih rukometaša iz Crne Gore - kvantitativni pristup" (Muratović, \& Georgiev, 2012), "Morfološki status finalista u bacačkim disciplinama na OI u Pekingu" (Pavlović, Radinović, \& Janković, 2012), "Uticaj morfoloških karakteristika i pojedinih motoričkih sposobnosti na selekciju u rukometu" (Isaković, Maksić, \& Vučković, 2012), "Nivo motoričkih sposobnosti netrenirane djece i djece koja su u trenažnom procesu različite sportske organizacije (karatisti i odbojkaši)" (Tatar, \& Karadžić, 2012), "Relacije između opštih motoričkih sposobnosti i testa "slalom sa loptom" učenika četvrtog razreda osnovne škole" (Ilić, \& Višnjić, 2012), "Rast i razvoj antropometrijskih karakteristika i motoričkih sposobnosti dečaka predškolskog uzrasta" (Pantović, Obradović, Batez, Dimitrić, \& Jadranski, 2012), "Antropometrijske karakteristike i motoričke sposobnosti mladih košarkaša Crne Gore" (Ljubojević, \& Nikolić, 2012), "Indeks tjelesne mase i efekti veslanja kajaka“" (Trivun, Tošić, Vuković, \& Pašić, 2012), "Povezanost motoričkih i morfoloških karakteristika učenika s' uspješnosti u takmičenju na $60 \mathrm{~m}$ " (Xhemajli, Myrtaj, \& Xhemajli, 2012), "Komparativna analiza motoričkih sposobnosti dve generacije fudbalera" (Tomić, Smajić, Radoman, Vujović, \& Ivančić, 2012), "Razlike u motoričkim sposobnostima dječaka i djevojčica mlađeg školskog uzrasta" (Orlić, Cvetković, Fratrić, Badža, \& Stupar, 2012), "Razlike u nivou situaciono-motoričkih sposobnosti fudbalera različitog ranga takmičenja" (Špirtović, Aćimović, \& Joksimović,
2012), "Uticaj motoričkih sposobnosti na efikasnost izvođenja osnovnog vijuganja u alpskom skijanju" (Hadžić, Vujović, \& Muratović, 2012), "Razlike između djevojčica mlađeg školskog uzrasta u intelektualnom funkcionisanju“" (Popović, Madić, Tumin, \& Jezdimirović, 2012), "Praćenje dinamike razvoja određenih antropoloških dimenzija kod učenika viših razreda osnovne škole“ (Džibrić, Mehinović, Malović, \& Čejvanović, 2012), "Efekti praktične nastave kursa za obuku spasilaca na vodi u transformaciji pojedinih antropoloških karakteristika" (Ćvetković, Radivojević, Dimitrić, Jadranski, Jakšić, \& Orlić, 2012), "Uticaj rekreativnog sinhronog plivanja na muzičke i intelektualne faktore i karakteristike ličnosti“ (Kocić, Tošić, Aleksić, \& Toskić, 2012), "Specifičnosti motoričkih sposobnosti fudbalera u odnosu na rang takmičenja“ (Lilić, \& Aleksić, 2012), "Ispoljavanje maksimalne izometrijske sile kod selektovanih rukometašica različitog uzrasta" (Maksić, Isaković, \& Vučković, 2012), "Relacije kognitivnih sposobnosti i koordinacije u ritmu" (Tumin, Madić, \& Popović, 2012), "Uticaj morfoloških karakteristika na preciznost u košarci“ (Myrtaj, 2012), "Uticaj motoričkih i morfoloških dimenzija na bacanje kugle srednjeg školskog uzrasta“" (Sylejmani, Maliqi, \& Bajrami, 2012), "Korelacioni odnosi motoričkih sposobnosti djevojčica 13 do 14 godina" (Naser, \& Ajvazi, 2012), "Uticaj biotope vrhunskih atletičara na brzinu trčanja svjetskog rekorda na $100 \mathrm{~m}$ " (Šolaja, M., Petrović, Mihajlović, \& Šolaja, A., 2012), "Specifičnosti mladih odbojkašica u motoričkom i intelektualnom funkcionisanju“ (Maksić, Isaković, \& Vučković, 2012), "Prediktivna vrijednost neke antropometrijske karakteristike na specifični motorički test mae geri u makedonskom karate klubu“ (Asani, Živković, \& Telai, 2012), "Struktura morfoloških karakteristika među fudbalerima - kadetski uzrast (14-16 godina)“ (Sylejmani, \& Maliqi, 2012), "Odnos između fizičke radne snage (PWC 170) i statičke relativne snage“ (Elezi, Besnik, \& Xhemajli, 2012), "Korelaciona analiza u antropološkom prostoru, motoričkih i kognitivnih dimenzija učenica srednje škole" (Bešović, M., Beganović, \& Bešović, H., 2012), "Promjene u nekim morfološkim karakteristikema omladine" (Elezi, Besnik, \& Beqa Ahmeti, 2012), "Nivo fizičke aktivnosti učenika srednjih škola na Kosovu" (Ibrahimi, Jashari, \& Jashari, 2012), "Uticaj morfoloških i bazično motoričkih sposobnosti na izvođenje situacionih zadataka u rukometu" (Xhemaili, 2012), "Korelacije morfoloških karakteristika i sportskog postignuća u karateu” (Bjelica, \& Petković, 2012), "Uticaj morfoloških karakteristika i motoričkih sposobnosti na izvođenje situacijskih kretnih struktura džudista" (Ilić, Mikić, Zeljković, \& Huremović, 2012).

Iz oblasti istraživanja u sportu i sociopsihologije u Sport Mont časopisu zastupljeni su slijedeći radovi: "Specifičnost motivacije u borilačkim sportovima“ (Ilić, \& Višnjić, 2012), "Povezanost percepcije sila ponašanja trenera i nivoa stresa $u$ fudbalu" (Tišma, Radoman, \& Vujović, 2012), "Skijanje na 
glečerima - savremeni trend aktivnog odmora i ekstremnih sportskih izazova" (Vujović, 2012), "Odnosi između domaćih i stranih košarakaša u košarkaškim ekipama" (Besnik, Gjonbalaj, Zhubaj, \& Elezi, 2012), "Kvalifikaciona struktura ljudskih resursa u sportu u opštinama Bijelo Polje, Mojkovac i Kolašin" (Jovanović, 2012), "Stavovi fudbalera različitog uzrasta o trenažnim sredstvima oporavka" (Smajić, Tomić, Radoman, Vujović, \& Ivančić, 2012), "Heuristička funkcija sporta" (Petrović, Milošević, \& Koprivica, 2012), "Uticaj biotope vrhunskih atletičara na brzinu trčanja svjetskoh rekorda na 100 m" (Šolaja, Petrović, Mihajlović, \& Šolaja, 2012), "Uticaj subjektivnog iskustva o značajkama fizičke aktivnosti na rekreativno vježbanje" (Čular, Žuvela, \& Lujan, 2012), "Nacionalni identitet vrhunskih sportaša" (Doupona, Topič, Rauter, Žvan, \& Coakley, 2012), "Struktura relacija nasilja i latentnih dimenzija ličnosti košarkaša predadolescenata" (Ivanović, Samardžić, B., Ivanović, \& Samardžić, P., 2012), "Problemi sa invaliditetom prikazivani u medijima" (Ranđelović, Pirsl, D., \& Pirsl, T., 2012), "Pozicija učenika i nastavnika u nastavi kao faktor sukoba u komunikaciji” (Ivanek, Mikić, Pinjuh, \& Karabašić, 2012), "Olimpijski pokret kao pokretač međunarodne saradnje i jačanja međudržavnih prijateljskih odnosa" (Simonović, \& Krivokapić, 2012), ,Sportske nauke i multikulturalizam - edukativni i profesionalni impakt” (Pirsl, D., Živanović, \& Pirsl, T., 2012).

U Sport Mont časopisu zastupljeni su i radovi iz sportske metodike, obrazovanje $i$ sport, menadžment $i$ marketing $u$ sportu: "Uloga nastavnika u procesu fizičkog vaspitanja (Branković, 2012), "Marketinška strategija sponzorstva u sportu" (Novaković, 2012), "Sportsko-tehničko obrazovanje studenta učiteljskog fakulteta" (Šekeljić, Stamatović, Bojović, \& Marković, 2012), "Efektivna vrijednost nastave plivanja u odnosu na kvalifikacioni ispit studenata" (Tošić, Trivun, Vuković, \& Panić, 2012), "Usvajanje nekih elemenata ritmičko sportske gimnastike kod učenika petog razreda" (Ahmeti, 2012), "Organizovanje marketing aktivnosti u sportskim organizacijama” (Župljanin, 2012), "Troškovno orijentisanje cene iznajmljivanja sportskih objekata" (Vukasović, Tadić, \& Malenković, 2012), "Đačka torba učenika osnovnoškolskog uzrasta" (Marković, Višnjić, Stamatović, \& Šekeljić, 2012), "Učitelj u nastavi fizičkog vaspitanja" (Stamatović, Šekeljić, Bojović, \& Marković, 2012), "Stavovi profesora fizičke kulture u oblasti ličnog usavršavanja, zadovoljstva poslom i razvoja sporta u Crnoj Gori““ (Bjelica, \& Krivokapić, 2012), "Obavezno osiguranje sportista u Srbiji” (Ostojić, S., \& Ostojić, N., 2012), "Savremena istraživanja snage u vrhunskom sportu" (Karadžić, \& Tatar, 2012), "Faktori menadžerske motivacije u karate sportu" (Nešić, \& Fratrić, 2012), "Umijeće sportskog menadžera u radu sa ljudima" (Čokorilo, Milošević, \& Grk, 2012), "Sportsko-tehničko obrazovanje studenta učiteljskog fakulteta" (Šekeljić, Stamatović, Bojović, \& Marković, 2012), "Finansijsko planiranje i finansiranje sportskih takmičenja" (Novaković, Đuranović, \& Vojinović, 2012), "Kreiranje menadžmenta u sistemu sportskih događaja" (Đuranović, Novaković, \& Gligović, 2012).

Radovi iz biomehanike, koja govori o tehnikama kretanja sportista i čovjeka (statika i dinamika) u Sport Mont časopisu, zastupljeni su slijedeći: "Flagellum" efekat u sportu" (Opavsky, 2012), "Držanje tijela kod učenika šestih razreda" (Beganović, Bešović, M., \& Bešović, H., 2012), "Uticaj vremena plivanja u pojedinim fazama plivanja na konačan rezultat u 50m disciplinama" (Dimitrić, Batez, Cvetković, Pantović, \& Jadranski, 2012), "Strukturalna i biomehanička analiza diska" (Bjeković, Tanović, Pavlović, Vuksanović, \& Arnaut, 2012).

Fiziologija sporta dio je medicine sporta, obuhvata sve vidove sporta $i$ tjelesnog vježbanja, i bavi se proučavanjem organizma i tjelesnih funkcija čovjeka. Radovi iz ove naučne oblasti su: "Eritropoetin kao doping sredstvo" (Đukanović, Mašić, Radotić, \& Kostovski, 2012), "Uticaj prirodnih stimulansa na čovjekov organizam" (Petković, \& Krivokapić, 2012).

Iz oblasti metodologije objavljeni su radovi: „Konstrukcija i validacija mjernog instrumenta za procjenu razine znanja vožnje monocikla" (Granić, Čular, \& Krstić, 2012), "Statistika u službi ocene kvaliteta" (Gardašević, \& Kružević, 2012), "Primena termovizije u trenažnom procesu u kendou" (Roglić, Fratrić, Nešić, Bjelica, \& Madić, 2012).

Sportska medicina kao poslednja oblast u ovom istraživanju. Obuhvatila je sledeće radove: „Kineziogenomatika kao primer personalizovane medicine“ (Vitošević, \& Kocić, 2012), "Povrede zbog prenaprezanja i njihovi uzroci u rekreativnih trkača u republici Sloveniji“ (Škof, Hadžić, \& Dervišević, 2012), "Razlike u posturalnom statusu kod učenika trećih razreda Osnovne škole“ (Džibrić, Biberović, Huremović, \& Bilalić, 2012), "Farmakološki pristup u tretmanu astme-indukovane vježbanjem" (Vitošević, Mitić, \& Nikolić, 2012), "Uticaj rekreacije na zdravlje čovjeka" (Tahiraj, Koničanin, Shabani, Shatri, Gjinovci, \& Gjonbalaj, 2012), "Prevencija posturalnih poremećaja kičmenog stuba kod djece I-IV razreda" (Gojković, \& Milinković, 2012), "Fizička aktivnost, percepcija zdravlja u studentskoj populaciji” (Lepeš, 2012).

\section{Diskusija}

U ovom istraživanju klasifikovane su teme iz Sport Mont časopisa, po oblastima, obuhvaćene kroz - 94 naslova. Metodom analize sadržaja došlo se do zaključka da su najbrojniji radovi iz antropologije sporta - 45 , zatim iz istraživanja u sportu i sociopsihologije - 15, radovi koji se tiču sportske metodike, obrazovanje i sport, menadžment i marketing u sportu obuhvatilo je -18 , oblast biomehanike obuhvatila je - 4, fiziologija sporta - 2, metodologija - 3, i na kraju, sportska medicina - 7 .

Imajući u vidu da je (period 2012. godine) u ovom istraživanju antropologija sporta dominantna oblast koja je proučavana u 45 radova, može se zaključiti da su nauke o čovjeku i u sportskom smislu toliko opširne da daju mogućnosti da se intenzivnije i na inovativniji način istražuje i dokazuje polje antropologije sporta. Svakako da su ta istraživanja od velikog značaja za sportska dostignuća kojima teži savremeni sport i da ima velikog prostora za unapređivanje samih sportista kroz sve savremenije instrumente i znanja koja se stvaraju i proširuju u okviru antropologije. Druga oblast u ovom istraživanju je oblast istraživanja u sportu i sociopsihologija (obuhvata 15 naslova) koja sama po sebi ima velikog uticaja u ljudskoj populaciji, pa naravno i u sportu. Oblast sociopsihologije koja je vezana za psihički život ljudi, šta ih vezuje, od čega zavisi i kako se manifestuje. Omogućava rješavanje problema društvenog života, u ovom smislu naslanjajući se na sport, oblasti i istraživanja koja su vezana za sport. Naredna oblast u ovom istraživanju jeste oblast sportske metodike, obrazovanja i sporta, kao i menadžment i marketing u sportu (obuhvata 18 naslova). Svakako da se veliki broj naslova bazira i na ove oblasti, prije svega jer su od velikog značaja za sportiste, spotske radnike koji kroz njih mogu na pravi način pomoći sebi i svojim potrebama kroz bavljenje sportom, bilo da su to potrebe nauke ili primjene rezultata u praksi. Oblasti iz biomehanike, fiziologije sporta, sportske medicine i metodologije sporta su nesumnjivo od velikog značaja za teoretičare, praktičare sporta i neupitno je njihovo napredovanje u nauci.

Utvrdilo se i da su objavljeni radovi imali za teme uglavnom savremene oblasti u sportskom naučnom svijetu. Ta istraživanja mogu biti korisna i za dalja teorijska i praktična istraži- 
vanja kojima se mogu poslužiti sportski radnici, u elektronskoj ili u pisanoj formi Sport Mont časopisa. Sa sigurnošću se može reći da će ovaj časopis nastaviti da opskrbljuje svoju arhivu re-

\section{R E F E R E N C E S}

Ahmeti, G. B. (2012). Acquisition of some elements of rhythmic sports ghymnastics by students of primary fifth grade. Sport Mont, 10(34-35-36), 600-4.

Asani, K., Zivkovic, V., \& Telai, B. (2012). Predictive value of some anthropometric characteristics on the specific motor test mae geri in macedonian members of the karate team. Sport Mont, 10(34-35-36), 542-5.

Beganovic, E., Besovic, M., \& Besovic, H. (2012). Body posture of students sixth grade pupils. Sport Mont, 10(34-35-36), 53-61.

Besovic, M., Beganovic, E., \& Besovic, H. (2012). Corealation analysis of the antropologcal space motor and cognitive dimensions of high school student. Sport Mont, 10(34-35-36), $62-74$

Bjekovic, G., Tanovic, I., Pavlovic, R., Vuksanovic, G., \& Arnaut, D. (2012). S tructural and biomechanical analysis of discus throw. Sport Mont, 10(34-35-36), 463-70.

Bjelica, D., \& Fratric, F. (2011). Sportski trening: teorija, metodika i dijagnostika. Nikšić: Fakultet za sport i fizičko vaspitanje Univerziteta Crne Gore.

Bjelica, D., \& Krivokapic, D. (2012). Attitudes of montenegrin professors of physical education in the field of personal specialization, work satisfaction and sports development in montenegro. Sport Mont, 10(34-35-36), 11-21.

Bjelica, D., \& Petkovic, J. (2012). Correlation of the morphological characteristics and sports achievements in karate. Sport Mont, 10(34-35-36), 616-20.

Bon, M., Cater T., \& Mojca D. (2012). Analysis of Slovenian womwn's handball - two worlds in a small country. Sport Mont 10(34-35-36), 27-33.

Brankovic, D., Martinovic, D., \& Ilic, J. (2012). Relations between general motor skills and handball specific test "ball slalom" in students of the iv grade of primary school. Sport Mont, 10(34-35-36), 188-93.

Coh, M., Zvan, M., \& Burnik, S. (2012). Differences in the reactive force of elite and sub-elite sprinters. Sport Mont, 10(34-35-36), 22-6

Cokorilo, R., Milosevic, Z., \& Grk, M. (2012). Skills of a sports manager in work with people. Sport Mont, 10(34-35-36), 339-45.

Cular, D., Zuvela, F., \& Lujan, I. K. (2012). Influence of subjective exercise experience on recreational exercising. Sport Mont, 10(34-35-36), 260-65.

Cvetkovic, M., Radivojevic, G., Dimitric, G., Jadranski, M., Jaksic, D., \& Orlic, D. (2012). Effects of practical classes of water lifesaving training course on transformation of particular anthropological characteristics. Sport Mont, 10(3435-36), 283-9.

Damjanovska, M. (2012). Relations between anthropometrical, motor and rhythmic variables of students ages 19-20. Sport Mont, 10(34-35-36), 128-134

Dimitric, G., Batez, M., Cvetkovic, M., Pantovic, M., \& Jadranski, M. (2012). Influence of swimming time in some phases on final result in 50m disciplines. Sport Mont, 10(34-3536), 124-7.

Dzibric, D., Mehinovic, J., Malovic, Z., \& Cejvanovic, I. (2012). Monitoring the development dynamics of certain anthropological dimensions in pupils of higher grades in levantnim i za nauku veoma korisnim istraživanjima sa ciljem da nastavi svoj put ka samom vrhu najčitanijih sportskih časopisa $u$ regionu.

Dzibric, D., Biberovic, A., Huremovic, T., \& Bilalic, J. (2012). Postural status differences in elementary school third grade pupils. Sport Mont, 10(34-35-36), 254-9.

Djuranovic, D., Novakovic, S., \& Gligovic, D. (2012). Creating a model of management in the security system of sports events. Sport Mont, 10(34-35-36), 408-18.

Djukanovic, N., Masic, Z., Radotic, F., \& Kostovski, Z. (2012). Erythropoietin as doping agent. Sport Mont, 10(34-35-36), 471-6.

Elezi, A., Morina, B., \& Xhemajli, M. (2012). Relation between the physical working capacity (pwc170) and static relative strength. Sport Mont, 10(34-35-36), 551-6.

Gardasevic, J., \& Bjelica, D. (2012). Validity of the situationalmotor tests with football players at the age of 15 . Sport Mont, 10(34-35-36), 488-92.

Gardasevic, D., \& Kruzevic, S. (2012). Statistics in service quality assessment. Sport Mont, 10(34-35-36), 587-93.

Georgiev, G., Kostovski, Z., \& Mitrevski, V. (2012). Quantitative differences in acquiring the motor tests with students from the republic of macedonia and republic of serbia. Sport Mont, 10(34-35-36), 105-9.

Gojkovic, D., \& Milinkovic, Z. (2012). Prevention of spinal disorders in childreni- iv grade. Sport Mont, 10(34-35-36), $75-82$

Granic, I., Cular, D., \& Krstic, T. (2012). Measuring instrument construction and validation in estimating unicycling skill level. Sport Mont, 10(34-35-36), 266-72.

Hadzic, R., Vujovic, D., \& Muratovic, A. (2012). Influence of motor capabilities on efficacy in performing wedge turning in alpine skiing. Sport Mont, 10(34-35-36), 477-81.

Halasi, S., \& Lepes, J. (2012). The relations between body composition and motorical skills by the children of age 7 . Sport Mont, 10(34-35-36), 89-93.

Ibrahimi, A., Jashari, V., \& Jashari, I. (2012). Level of physical activity of secondary school students in kosovo. Sport Mont, 10(34-35-36), 579-86.

Ilic, M., Mikic, B., Zeljkovic, M., \& Huremovic, D. (2012). Influence of the morphological characteristics and motor abilities on performing situational movement structures in judo. Sport Mont, 10(34-35-36), 573-8.

Ilic, J., \& Visnjic, D. (2012). Specifics of motivation in combat sports. Sport Mont, 10(34-35-36), 181-7.

Isakovic, M., Maksic, Z., \& Vuckovic, G. (2012). The influence of morphological characteristics and specific motor skills on selection in handball. Sport Mont, 10(34-35-36), 312-9.

Ivanek, P., Mikic, B., Pinjuh, K., \& Karabasic, J. (2012). The position of students and teachers in the teadhing of conflict as a factor in communication. Sport Mont, 10(34-35-36), $563-72$.

Ivanovic, M., Samardzic, B., Ivanovic, U., \& Samardzic, P. (2012). Structure relation of violence and personality latent dimensions of preadolescent basketball players. Sport Mont, 10(34-35-36), 456-62.

Jovanovic, M. (2012). Qualification structure of human resources in sport in municipalities bijelo polje, mojkovac i kolasin. Sport Mont, 10(34-35-36), 207-12.

Karadzic, P., \& Tatar, N. (2012). Modern research in high qua- 
lity sport. Sport Mont, 10(34-35-36), 142-8.

Kljajevic, V. (2012). The influence of electoral program of volleybal and basketbal on the transformation biomotoricaly ability students. Sport Mont, 10(34-35-36), 378-83.

Kocic, J., Tosic, S., Aleksic, D., \& Toskic, D. (2012). The influence of recreative synchronized swimming on music and intellectual factors and personal characteristics. Sport Mont, 10(34-35-36), 508-50.

Lepes, J. (2012). Physical activity, perceived health and welness in a college population. Sport Mont, 10(34-35-36), 521-8.

Lilic, L., \& Aleksic, D. (2012). The specifics of motor abilities of football players in relation to the rank of competition. Sport Mont, 10(34-35-36), 290-7.

Ljubojevic, M., \& Nikolic, B. (2012). Antropometric characteristics and motor skills of young montenegro basketball players. Sport Mont, 10(34-35-36), 174-80.

Maksic, Z., Isakovic, M., \& Vuckovic, G. (2012). Manifestation of maximal isometric muscle strength among selected female handball players of different ages. Sport Mont, 10(34-35-36), 346-53.

Maksic, Z., Isakovic, M., \& Vuckovic, G. (2012). The influence of morphological characteristics and specific motor skills on selection in handball. Sport Mont, 10(34-35-36), 312-9.

Markovic, M., Brankovic, D., Ljubojevic, M., \& Visnjic, D. (2012). Comparative analysis of physical education syllabus for junior school age in some european countries. Sport Mont, 10(34-35-36), 194-200.

Markovic, Z., Visnjic, D., Stamatovic, M., \& Sekeljic, G. (2012). A primary school pupil's school bag. Sport Mont, 10(34-35-36), 384-90.

Martinovic, D., \& Brankovic, D. (2012). Teacher's role in the physical education process. Sport Mont, 10(34-35-36), 1004.

Mihajlovic, I., Petrovic, M., \& Solaja, M. (2012). Differences in manifestation of explosive power of legs regarding to longitudinal foot arch in young athletes. Sport Mont, 10(3435-36), 47-52.

Mitrevski, V., Georgiev, G., \& Kostovska, Z. (2012). Relation between the latent motor dimensions responsible for movements of students in acquiring the motor tests. Sport Mont, 10(34-35-36), 628-36.

Muratovic, A., \& Georgiev, G. (2012). Basic motor abilities and situational motor efficiency with young handball players from montenegro - quantitative approach. Sport Mont, 10(34-35-36), 493-8.

Morina, B., Gjonbalaj, M., Zhubaj, V., \& Elezi, A. (2012). Relations between domestic and foreign basketball player in basketball t eam. Sport Mont, 10(34-35-36), 157-62.

Myrtaj, N. (2012). Effect of morphological characteristics of precision in basketball. Sport Mont, 10(34-35-36), 298-304.

Naser, N. R., \& Ajvazi, V. (2012). Canonical relation motor abilities of girls, from 14 to 15 years of age. Sport Mont, 10(34-35-36), 333-8.

Nesic, M., \& Fratric, F. (2012). Managerial factors of motivation in karate sport. Sport Mont, 10(34-35-36), 273-82.

Novakovic, S. (2012). Marketing strategy in sports sponsorship. Sport Mont, 10(34-35-36), 425-33.

Novakovic, S., Đuranovic, D., \& Vojinovic, Z. (2012). Financial planning and financing of sports competitions. Sport Mont, 10(34-35-36), 419-24.

Opavsky, P. (2012). "flagellum" efekat u sportu. Sport Mont, 10(34-35-36), 3-10.

Orlic, D., Cvetkovic, M., Fratric, F., Badza, V., \& Stupar, D. (2012). Differences in motor abilities of boys and girls of younger school age. Sport Mont, 10(34-35-36), 305-11.

Ostojic, S., \& Ostojic, N. (2012). Insurance of athletes in serbia. Sport Mont, 10(34-35-36), 273-82.

Pantovic, M., Obradovic, J., Batez, M., Dimitric, G., \& Jadranski, M. (2012). Growth and development of anthropometric characteristic and motorical abilities of preschool boys. Sport Mont, 10(34-35-36), 116-23.

Pavlovic, R., Radinovic, Z., \& Jankovic, M. (2012). The morphological status of the finalist in throwing disciplines at the beijing olympics. Sport Mont, 10(34-35-36), 447-55.

Petkovic, J., \& Krivokapic, D. (2012). The effects of natural stimulants on the human organism. Sport Mont, 10(34-35-36), 621-7.

Petrovic, A., Milosevic, V., \& Koprivica, V. (2012). The heuristic function of sport. Sport Mont, 10(34-35-36), 223-8.

Pirsl, D., Zivanovic, N., \& Pirsl, T. (2012). Sports sciences and multiculturalism - educational and professional impact. Sport Mont, 10(34-35-36), 644-50.

Popovic, S. (2012). Usage of athletes as endorsers. Sport Mont, 10(34-35-36), 110-5.

Popovic, B., Madic, D., Tumin, D., \& Jezdimirovic, T. (2012). Differences in intellectual functioning between girls at younger school age. Sport Mont, 10(34-35-36), 39-46.

Randjelovic, N., Pirsl, D., \& Pirsl, T. (2012). Issues on disability advertising imaging in media. Sport Mont, 10(34-3536), 536-41.

Roglic, G., Fratric, F., Nesic, M., Bjelica, D., \& Madic, D. (2012). Thermovision application in kendo training. Sport Mont, 10(34-35-36), 637-43.

Sekeljic, G., Stamatovic, M., Bojovic, Z., \& Markovic, Z. (2012). Sports and tehnical education for tzhe students of teaching faculty. Sport Mont, 10(34-35-36), 395-400.

Simonovic, D., \& Krivokapic, D. (2012). The olympic games as actuator of an international cooperation and strengthening of interstate friendly relations. Sport Mont, 10(34-3536), 605-10.

Skof, B., Hadzic, V., \& Dervisevic, E. (2012). Frequency and risk factors for overuse injuries of lower extremity in slovenian recreative runners. Sport Mont, 10(34-35-36), 354-9.

Smajic, M., Tomic, B., Radoman, M., Vujovic, P., \& Ivancic, G. (2012). Attitudes of football players of different age on training exercises of recovery. Sport Mont, 10(34-35-36), 213-7.

Solaja, M., Petrovic, M., Mihajlovic, I., \& Solaja, A. (2012). High performance runners' biotype influence on 100 metres world record running speed. Sport Mont, 10(34-35-36), 611-5.

Spirtovic, O., Acimovic, D., \& Joksimovic, A. (2012). Differences in the level of situational -motor abilities of football players of different level competitions. Sport Mont, 10(3435-36), 391-4.

Stamatovic, M., Sekeljic, G., Bojovic, Z., \& Markovic, Z. (2012). Teacher in physical education. Sport Mont, 10(3435-36), 401-7.

Sylejmani, B., \& Maliqi, A. (2012). Structure of morphologic characteristics among football players - cadet age (14-16 years old). Sport Mont, 10(34-35-36), 546-50.

Sylejmani, B., Maliqi, A., \& Bajrami, S. (2012). The impact of motor and morphologic dimensions with putting the shot upon high school students. Sport Mont, 10(34-35-36), 3205.

Tatar, N., \& Karadzic, P. (2012). Level of motor abilities of children untrained and children that were in the training process a variety of sportsorientation (karate and volleyball). Sport Mont, 10(34-35-36), 149-56. 
Tahiraj, E., Konicanin, A., Shabani, A., Shatri, F., Gjinovci, B., \& Gjonbalaj, M. (2012). The impact of recreational in human health. Sport Mont, 10(34-35-36), 499-507.

Tisma, M., Radoman, M., \& Vujovic, P. (2012). Relation in perception of the style of behaviour of the coach and the level of stress in football. Sport Mont, 10(34-35-36), 135-41.

Tisma, M., Radoman, M., \& Vujovic, P. (2012). Relation in perception of the style of behaviour of the coach and the level of stress in football. Sport Mont, 10(34-35-36), 135-41.

Tomic, B., Smajic, M., Radoman, M., Vujovic, P., \& Ivancic, G. (2012). Comparative analysis of motor abilities of two generations of football players. Sport Mont, 10(34-35-36), 218-22.

Topic, M. D., Rauter, S., Zvan, M., \& Coakley, J. (2012). National identity of top - level athletes. Sport Mont, 10(34-3536), 372-7.

Trivun, M., Tosic, J., Vukovic, S., \& Pasic, G. (2012). Body mass index and effects during kayaking. Sport Mont, 10(3435-36), 236-46.

Tumin, D., Madic, D., \& Popovic, B. (2012). Relations of cognitive skills and coordination in rhythm. Sport Mont, 10(3435-36), 94-9.

Vitosevic, B., \& Kocic, J. (2012). Kinesiogenomics as an example of personalized medicine. Sport Mont, 10(34-3536), 167-73

Vitosevic, B., Mitic, R., \& Nikolic, I. (2012). Pharmacological approach in exercise-induced asthma. Sport Mont, 10(3435-36), 163-6.
Vuleta, D., Milanovic, D., \& Nikolic, A. (2012). Differences between cadet and younger cadet handball players in specific motor abilities. Sport Mont, 10(34-35-36), 34-8.

Vujovic, V. (2012). Skiing on glaciers - a modern trend of active holidays and extreme sports challenges. Sport Mont, 10(34-35-36), 83-8.

Vujovic, D. (2012). The influence of rhytmic gymnastics teaching contents upon development of some motor skills among the schoolgiris of the fifth grade of primary school. Sport Mont, 10 (34-35-36), 482-7.

Vukasovic, D., Tadic, O., \& Malenkovic, N. (2012). Cost-oriented prices to rent sports facilities. Sport Mont, 10(34-3536), 434-9.

Vukasovic, D., Tadic, O., \& Malenkovic, N. (2012). Pricing of products in the sports tourism. Sport Mont, 10(34-35-36), 440-6.

Vukovic, M., \& Pocek, S. (2012). Specific features of young volleyball players in motor and intelectual functioning. Sport Mont, 10(34-35-36), 360-71.

Xhemajli, V., Myrtaj, N., \& Xhemajli, A. (2012). Relationship between motor and morphological characteristics of students with success in running to 60 meters. Sport Mont, 10(34-35-36), 201-6.

Xhemaili, M. (2012). The impact of morphological and basic motor dimensions on performing the situational-motor duty in handball. Sport Mont, 10(34-35-36), 594-9.

Zupljanin, S. (2012). Marketing organization activity in sports organizations. Sport Mont, 10(34-35-36), 529-35.

\section{J. Radulovic}

University of Montenegro, Faculty for Sport and Physical Education, Narodne omladine bb, 81400, Niksic, Montenegro e-mail: Jovan.radulovic92live@ac.me 